\title{
Influence of the Hardfacing Welds Structure on Their Wear Resistance
}

\author{
Janette Brezinová *, Dagmar Draganovská, Anna Guzanová, Peter Balog and Ján Viňáš \\ Department of Mechanical Technology and Materials, Technical University of Košice, Mäsiarska 74, \\ 04001 Košice, Slovakia; dagmar.draganovska@tuke.sk (D.D.); anna.guzanova@tuke.sk (A.G.); \\ peter.balog@tuke.sk (P.B.); jan.vinas@tuke.sk (J.V.) \\ * Correspondence: janette.brezinova@tuke.sk; Tel.: +421-55-602-3542
}

Academic Editor: Hugo F. Lopez

Received: 14 December 2015; Accepted: 26 January 2016; Published: 17 February 2016

\begin{abstract}
The contribution presents the research results of hardfacing metals' resistance in conditions of abrasive wear. Two types of hardfacing electrodes with a different chemical composition were used in the creation of three layers of hardfacing metals. The chemical composition of electrodes determines the difference in a hardface deposit structure. We have investigated the influence of mixing the base metal and a filler metal and the influence of hardfacing welds structure on the resistance against abrasive wear. The results of the experiments have showed that the intensity of wear is very dependent on the parameters of wear as well as the morphology structure of hardfacing metals.
\end{abstract}

Keywords: hardfacing welds; structure; abrasive wear; wear resistance

\section{Introduction}

The wear of mechanical parts of machinery is still a current scientific, engineering and economic issue. The analysis of machine parts and structure faults shows they are often caused by tribological processes that take place at the functional surfaces. The interaction between functional surfaces in their relative motion causes adverse effects in the surface layers, leading to their deterioration. An external manifestation of this process is the removal or relocation of the functional surface particles. This process can be measured by a change in the size, weight or mechanical and physico-chemical properties. This process can be alleviated by improving the structural arrangement of nodes, the appropriate choice of materials or the creation of new surface layers [1-5]. When creating the surface layers for tribological use, we often encounter hardfacing technology which enables not only the restoration of the worn surface geometry but gives it new, often better properties than the properties of the original material, which leads to a prolongation of their life [6-8].

Welding consumables can be divided into groups according to their properties and wear resistance. The iron-based alloys include martensitic alloys, austenitic alloys and alloys with a high content of carbides [9]. Martensitic alloys are used for the restoration of shape and for hardfacing. Their main advantages include good resistance to wear of metal-metal type, good impact resistance and acceptable abrasion resistance.

Austenitic claddings are suitable for the restoration of shape and are characterized by an excellent impact resistance and an acceptable abrasion resistance.

The advantage of alloys with high carbide content is both the excellent abrasion resistance, good heat resistance, and acceptable corrosion resistance; however, the disadvantage is a weak impact resistance [10].

Cobalt- and nickel-based alloys are resistant to most types of wear. Due to their high cost, they are only used in cases when their properties are economically justified, such as in high temperature applications when the iron-based alloys with a high carbide content lack sufficient resistance. Nickel alloys are a slightly cheaper alternative [11]. 
The most progressive additive materials for welding and thermally sprayed coatings for the conditions of abrasive, erosive, corrosive and combined stresses in mining, energy and building industries include nanostructural claddings [12]. Characteristics of these materials not containing cobalt or nickel are based on the high content of carbide-forming and boride-forming metals $\mathrm{Cr}$, Mo, $\mathrm{W}$ and $\mathrm{Nb}$, carbon (up to $5 \%$ ) and boron (5\%-10\%). They have an amorphous metallic glass character. Very hard and very fine nanostructures with a grain size of 2-75 nm are formed during their devitrification. A hardness of 900-1230 HV, 54-74 HRC, respectively, is reached by the resulting cladding. The base element in these alloys is iron even though, in the maximum content of alloying elements, it does not reach $50 \%$. The claddings are carried out by MIG (Metal Inert Gas) hardfacing, and coatings are carried out by HVOF (High Velocity Oxygen Fuel) and plasma spraying technology.

Essential scientific knowledge of cladding tribology is detailed in $[13,14]$ and others. These imply that one of the determining factors for the wear intensity in both the abrasive and erosive wear of claddings is their hardness. The hardness of cladding is a function of its chemical composition, the welding heat mode during hardfacing and its structure.

In the current analysis of abrasion resistance, the issue of cladding structure and substructure and their influence on abrasion resistance is not analyzed in detail. So far there is no consensus on the most appropriate type of structure in terms of resistance to abrasive wear. Most authors coincide in finding that the resistance to abrasive wear of alloys with the same hardness with a different chemical and structural composition is not the same. This depends on the hardness, the amount, the shape, the size and the distribution of structural components. Some authors consider austenitic-carbidic the most advantageous structure, others prioritize a martensitic-carbidic structure. This results from the diversity of the abrasive wear process and a wide range of real operating conditions [6,9,15-17].

Structural and substructural properties can directly affect material removal. Its intensity is conditioned by the strength and cohesive properties of the submicroscopic particles of structure that are loaded by wear and abrasion. Every structural component in the process of exploitation determines the level of resistance of the whole metal with its share. In abrasive wear, two crucial stages must be distinguished. The first one is the process of forcing the abrasive into the surface where the limiting factor is the indentation hardness. The second stage is the process of surface disintegration, where the crucial role belongs to the strength of interatomic bonds and the strength of the structural components' connection to each other at the grain boundaries [13].

In real conditions, the failure of the material surface layers by a high-cycle contact fatigue process (abrasive particles do not notch into the surface, causing only elastic deformation), a low-cycle contact fatigue process (a plastic deformation when notching abrasive particles into the surface) and the grooving together with the segregation of worn material particles may occur at various locations of the tough material-worn surface. At a high speed of abrasive particles' relative motion against the worn surface, it is necessary to also consider other degradation mechanisms: the heat affection of the material (tempering of steel, softening of the polymeric material), adsorption failure (reactions of the worn material with surface active agents that reduce surface hardness) and tribochemical reactions of the worn material with the environment. Although in abrasive wear of brittle materials plastic deformation occurs, the brittle fracture often determines the rate of wear. In tough materials this fault occurs probably right after the abrasive particle, due to tensile stress, acts here. The removal of the material by abrasion in brittle materials occurs by a brittle fracture rather than by the plastic deformation. Also, in the abrasive wear of heterogeneous materials which contain tough and brittle phases, infringement by brittle fracture may occur. The predominant mechanism of material removal depends on the characteristics of individual phases and their volume fractions [14].

The stated information implies that due to the complexity of the wear process, it is necessary to design a type of cladding based on the tribological analysis and the conditions of the surface stress. This analysis, however, is for many practical cases impracticable due to the imperfection of developed procedures and, therefore, operational and laboratory tests have recently been used for the evaluation of cladding properties. 
The aim of the paper is to carry out a tribological and metallographical analysis for two types of hardfacing layers. The analysis can contribute to clarification of the relationship between the microstructure and wear resistance of layers.

\section{Materials and Methods}

The base material for production of hardfacing samples also used as a gauge in the tests of wear was steel of grade S235JRH. Dimensions of the test samples were $20 \times 20 \times 8 \mathrm{~mm}$. This is a structural carbon steel with $0.22 \% \mathrm{C}$ and excellent weldability.

For cladding formation hardfacing electrodes E 508 B and E 518 B (Welding Research Institute, Industrial Institute of Slovakia, Bratislava, Slovakia) were used, whose chemical composition meets the requirements for heterogeneity of structural constitution of claddings. Chemical composition of electrodes is shown in Table 1. Technological and use properties are as follows:

- $\quad$ E 508 B-thick flux-covered electrode. Recommended preheating: without preheating or preheating up to $250{ }^{\circ} \mathrm{C}$, depending on the quality and dimensions of the hardfacing component. It is used for hardfacing of working parts of agricultural and forestry machines exposed to abrasion. The cladding is resistant to mild impacts, it is not thermally treated. If any treatment is needed, it shall be spheroidizing annealed and subsequently thermally treated to optimal hardness of approximately $600 \mathrm{HV}$ (Vickers hardness).

- $\quad$ E 518 B-thick flux-covered electrode. Cladding preferably alloyed from the flux cover. Preheating for hardfacing is $400{ }^{\circ} \mathrm{C}$ with following cooling in wrap or in the oven. Cladding is not thermally treated. It is used for the parts of mining and earth-moving machinery, metallurgical equipment exposed to abrasive and erosive wear combined with impacts. Hardness of the cladding is $600-660 \mathrm{HV}$.

Table 1. Chemical composition and hardness of welding electrodes in wt. \%.

\begin{tabular}{ccccccc}
\hline Electrode & C & Mn & Si & Cr & Mo & HV \\
\hline E 508 B & 0.5 & 0.7 & 0.5 & 6.0 & 0.6 & 580 \\
E 518 B & 3.4 & 0.5 & 0.8 & 29 & - & 660 \\
\hline
\end{tabular}

Cladding samples for the studies of structural condition and the fracture surfaces were made from one to three layers. After cooling the cladding was broken off by three-point bending. The surfaces obtained this way were used to study the failure mechanism and for the structural analysis. Abrasion resistance was determined with an assistance of a test device based on the principle of relative movement of test samples submerged into free abrasive [16]. For this test abrasive based on $\mathrm{Al}_{2} \mathrm{O}_{3}$ with grain size of $1.2 \mathrm{~mm}$ was used. Incidence angle between abrasive and test sample was $75^{\circ}$ and speed of relative sample motion was $2.25 \mathrm{~m} \cdot \mathrm{s}^{-1}$. The weight losses were investigated using sensitive digital scale weight with a measurement accuracy of $10^{-4} \mathrm{~g}$.

To determine the microhardness of individual structural phases, the microhardness HV0.05 was measured, with a load of $0.5 \mathrm{~N}$ and dwell time $10 \mathrm{~s}$. The measurements were carried out using Hannemann head (Carl Zeiss AG, Feldbach, Switzerland). The course of the hardness in the cross-section of claddings was realized by the Vickers hardness pyramid (HPO 250, Liepzig, Germany) with a load of $294.3 \mathrm{~N}$ and dwell time $10 \mathrm{~s}$.

Metallographic study and a study of fracture surfaces were realized using light microscope Olympus BXFM (Olympus Deutschland GmbH, Hamburg, Germany) and a scanning electron microscope TESLA-BS-301 (Tesla, Brno, Czech Republic).

\section{Results and Discussion}

The course of the hardness of claddings E 508 B showed a strong effect of mixing the weld and base metal, as shown in Figure 1. The hardness of the cladding in its first layer in the area of melting 
rises sharply to a value of $550 \mathrm{HV} 30$. The second layer reaches an average value of $615 \mathrm{HV} 30$, while in three-layer cladding the hardness reaches around 630 units. Theoretical and practical assumptions that the effect of mixing the base material and weld metal does not disappear until the third layer were confirmed [13]. The transition of the hardness curves from the minimal values of the base material to the maximum values in the cladding showed a step-change.

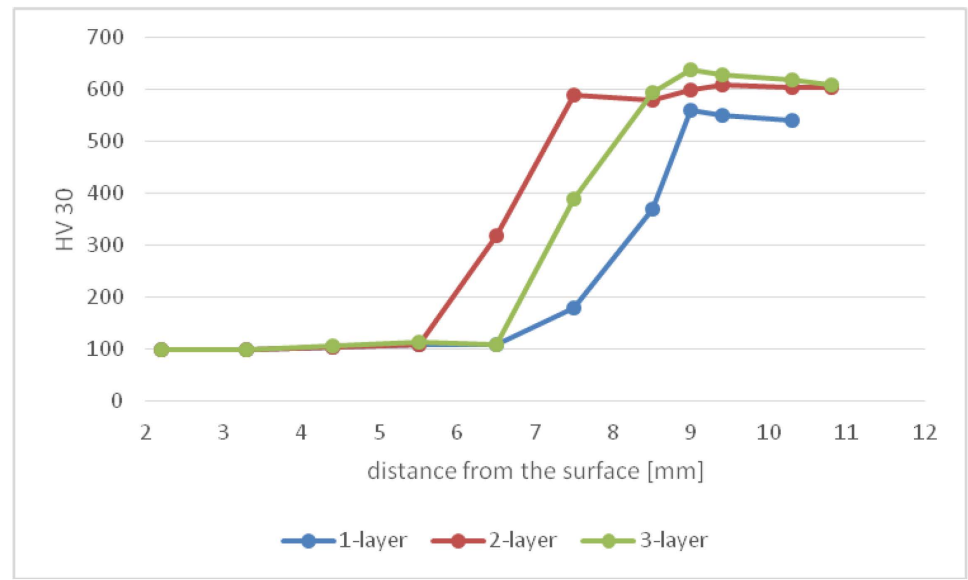

Figure 1. Course of hardness in cladding E 508 B with various numbers of layers.

A similar course of the hardness was shown by cladding E 518 B, except that the hardness value stated by the manufacturer, which is $660 \mathrm{HV} 30$, was reached already in the first layer. Maximum values obtained in individual layers did not differ significantly and reached up to $730 \mathrm{HV}$. Due to the high content of $\mathrm{C}$ and $\mathrm{Cr}$, the mixing with the base material was significantly less.

The course of three-layer cladding hardness is shown in Figure 2. In terms of achieved hardness, higher wear resistance can be assumed in claddings realized by the E 518 B electrode.

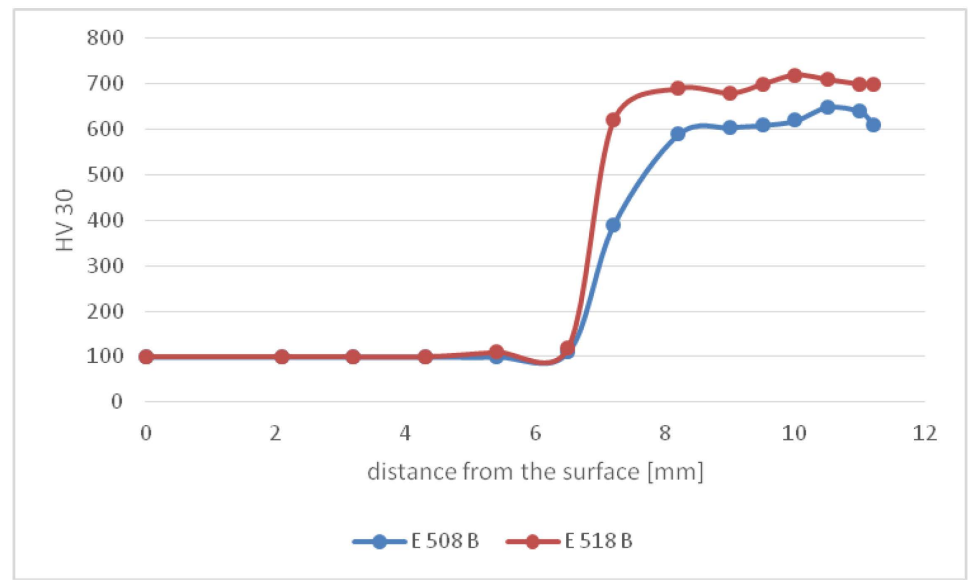

Figure 2. Course of hardness in three-layer hard-faced materials.

The results of abrasion resistance tests of evaluated hardfaced materials are graphically presented in Figures 3 and 4. From these figures it can be seen that, in electrode E 508 B, single-layer claddings show higher mass loss due to the mixing of the weld metal with low-carbon steel. Despite the fact that for electrode E 518 B small differences of hardness values were reached in individual layers, there is a big difference in mass loss between single-layer and multiple-layer claddings. Compared to electrode E 508 B, it reaches higher values. The results of mass loss values of tested claddings cannot be evaluated just by a chemical composition and measured values of hardness. Most authors 
explain the theory of material removal in wear by a contact interaction where a plastic deformation occurs [6]. This deformation is caused by the redistribution and dissipation of energy. The energy redistribution, followed by implementation of plastic deformation, causes a movement of anchored and free dislocations. The dislocation state of metals depends mainly on the structural state. The real structural state is therefore another factor influencing the wear resistance $[13,15]$.

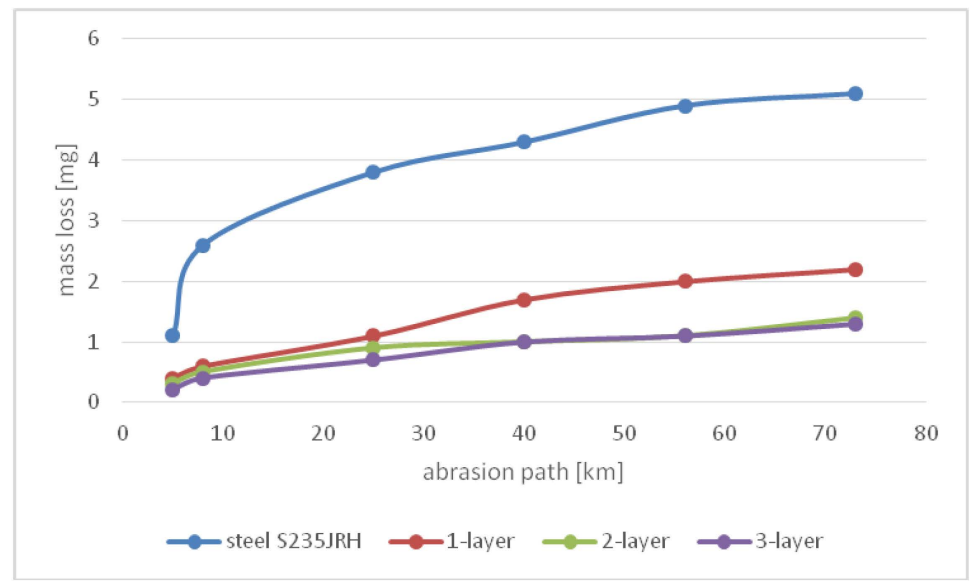

Figure 3. Course of wear for hardfacing material E 508 B.

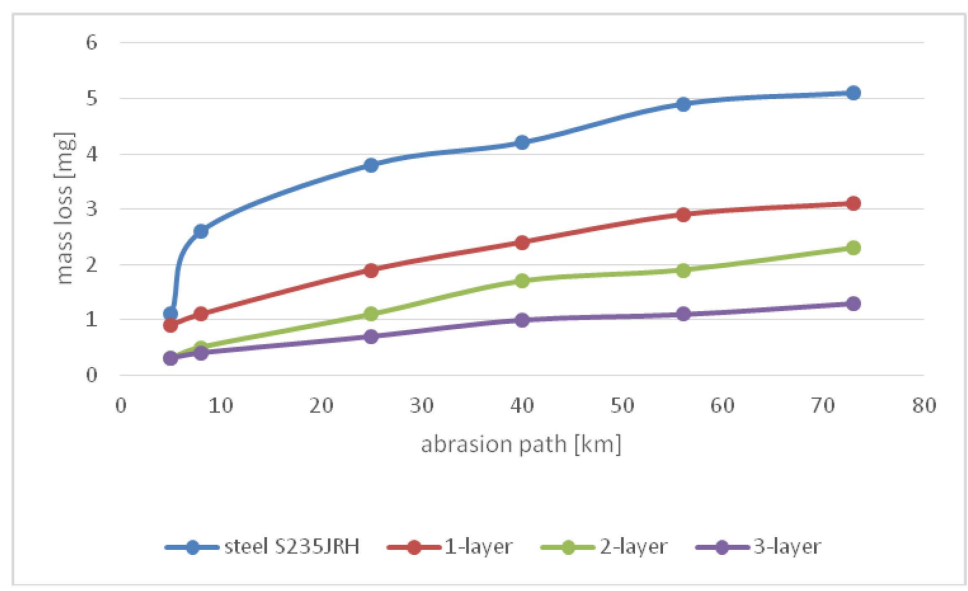

Figure 4. Course of wear for hardfacing material E 518 B.

As mentioned above, the investigated claddings vary significantly in internal structure. Electrode E $508 \mathrm{~B}$ represents cladding based on mild steel with a content of $\mathrm{C}$ up to $0.4 \%$. The relatively high content of carbide-forming elements $\mathrm{Cr}$ and Mo determines the formation of the bainitic matrix structure and, by bonding with carbon, creates disperse carbides reinforcing the very fine bainitic matrix. Since claddings are multilayered and multipass in a layer, the mutual thermal influence causes very heterogeneous formation of the phases. In Figure 5 there is a structure of the first layer in the area of the mixing of the weld metal with the base material which was not thermally affected. It is a very fine bainitic structure with a ferrite net which retains the oriented nature. The microhardness of this layer reaches $424 \mathrm{HV}$ 0.05. In the area of thermal affection, the grains are finer and the distinctive casting character is disappearing, as shown in Figure 6. The similar nature of the structure is also present in the second layer, where the hardness reaches $489 \mathrm{HV} 0.05$. In the third layer of the cladding, which was not thermally affected, the distinctive casting structure is retained, as shown in Figure 7 (538 HV 0.05). The cladding structure in the third layer in the thermally affected zone is shown in Figure 8. In the bainitic matrix, the very dispersely formed carbidic phase can be observed. Claddings are 
thus characterized by a relatively tough matrix in which the very disperse carbidic phase ensures sufficiently high hardness and, therefore, abrasion resistance.

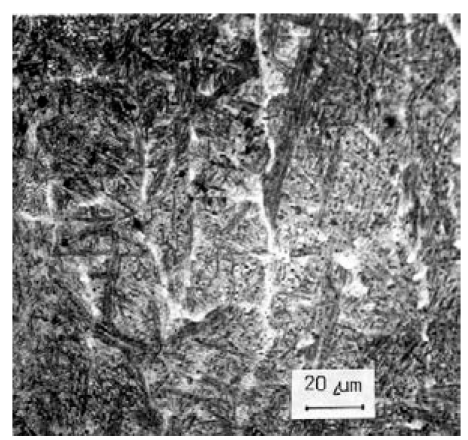

Figure 5. Microstructure of hardfacing weld E 508 B.

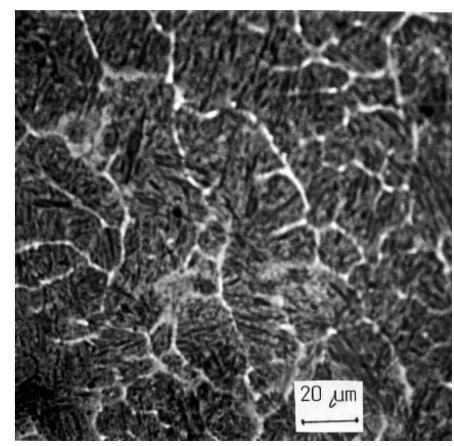

Figure 6. Thermally affected structure of the cladding E 508 B.

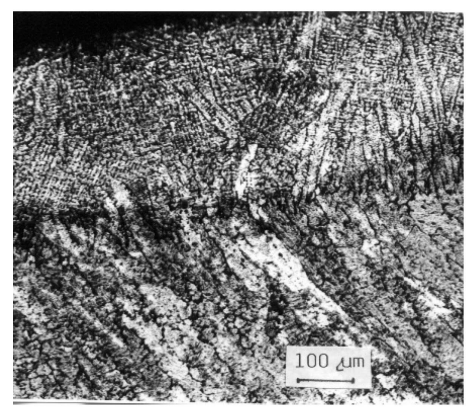

Figure 7. Cast structure of hardfacing weld E 508 B.

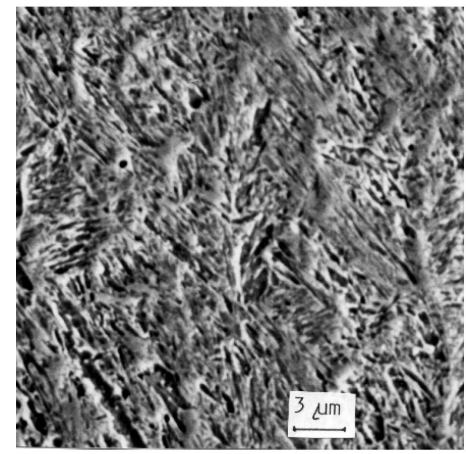

Figure 8. Carbidic phase in bainitic matrix of the weld E 508 B. 
The structural composition of the claddings realized by electrode E 518 B is shifted into the area of cast iron, which is manifested by the significant dendritic character of the cast structure. The high content of C up to $3.5 \%$ and chrome up to $27.5 \%$ after the re-melting in the cladding gives a high-alloyed cast iron of ledeburitic type with a significant presence of primary and secondary carbides. The structure in the transition from the base material to the cladding is documented in Figure 9. Figure 9 shows that even in the short term of the re-melting, a very thin carburized layer was formed in the base material, demonstrated by large pearlitic grains. In the areas of the cladding where the cast structure was thermally affected, a very fine, oriented needle structure (Figure 10) or a transformed structure with large carbidic needles (Figure 11-TMP14) was formed due to the structural transformation. The structure in the cover layers of the cladding is a casting structure with a distinct dendritic composition (Figure 12). The average hardness of the ledeburitic matrix was of $562 \mathrm{HV} 0.05$. Large carbidic needles reached a hardness of $1630 \mathrm{HV} 0.05$ while small needles reached up to $2350 \mathrm{HV} 0.05$.

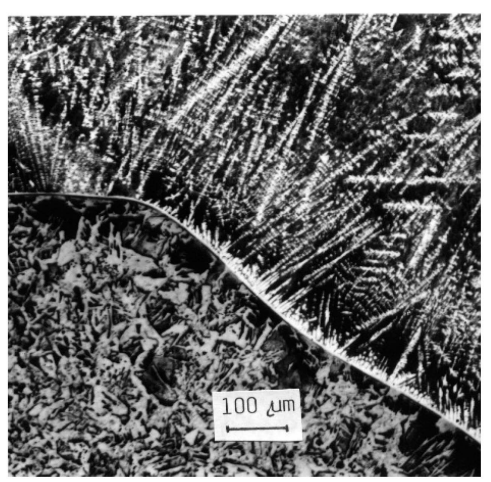

Figure 9. Cast structure of hardfacing weld E 518 B.

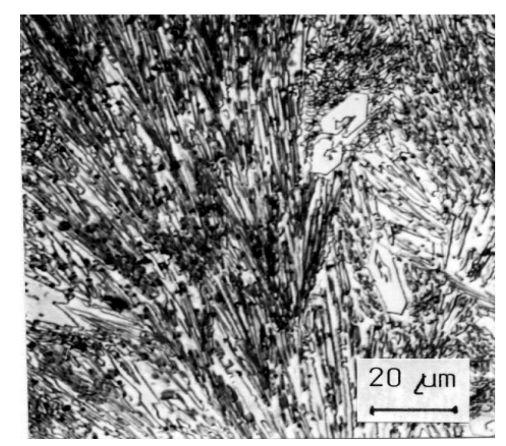

Figure 10. Detail of fine-grain structure of cladding E 518 B.

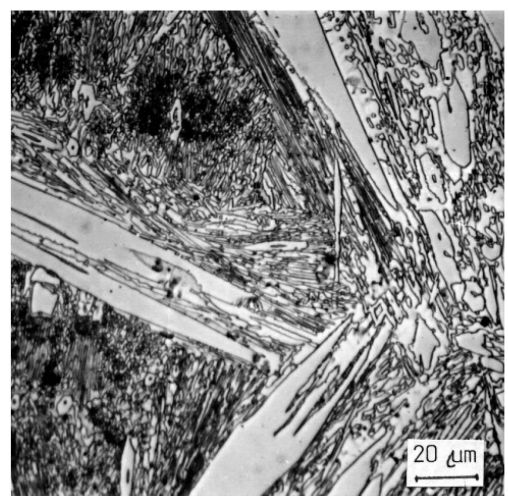

Figure 11. Detail of massive carbidic particles E 518 B. 


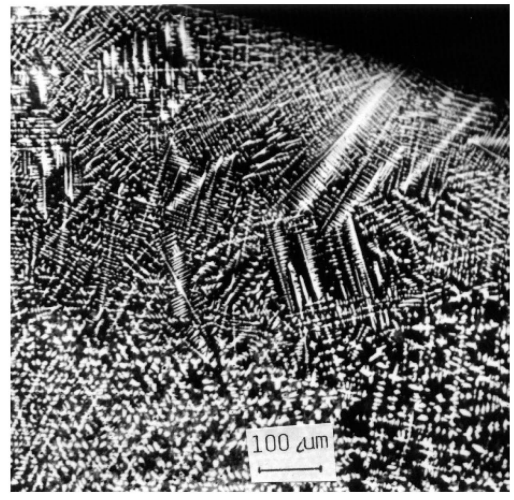

Figure 12. Cast structure of hardfacing weld E 518 B.

For the creation of the fracture surface, energy is demanded and, thus, the character of the fracture, whether it is cleaving, ductile failure or decohesion along the phase boundary, also provides the resistance to separation of microparticles under surface abrasion. Therefore, the examination of these surfaces makes it possible to predict the use properties of metallic materials.

Depending on the heat affection of the structural composition, the bulk of the fracture surfaces of E 508 B under bending stress was formed by decohesive failure at the border of crystallites or dendrites, as shown in Figure 13. Part of the surface failed by decohesion with a low power consumption - smooth facets and part of the surface failed in these claddings by pit morphology whose creation is energy-demanding and indicates the certain resistance to a brittle fracture, as shown in Figure 14.

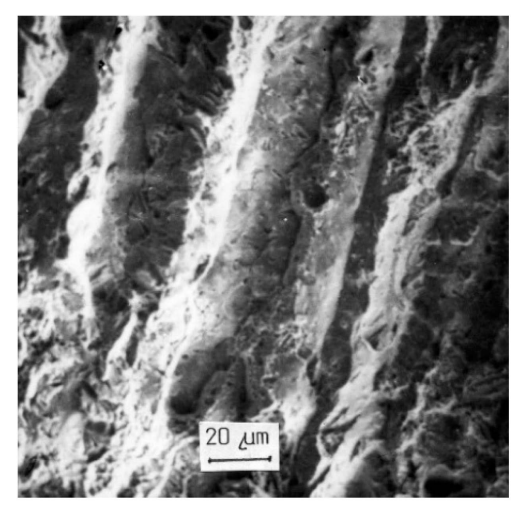

Figure 13. Decohesive failure at the dendrite borders.

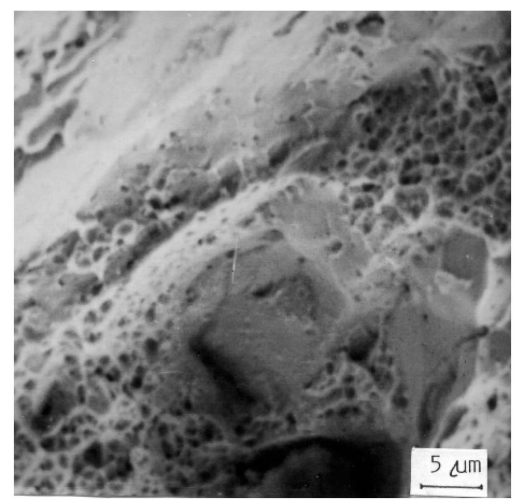

Figure 14. Morphology of E 508 B cladding failure. 
The fracture surfaces of claddings of E 518 B obtained for the purpose of studying the mechanism of their formation confirm that the energy demand for their creation is very low. The view of the fracture surface is shown in Figure 15. Part of the fracture surface consists of decohesive facets without morphological signs of cleaving or ductile failure. Their formation has occurred by the simple separation of the surfaces at the grain borders with minimum energy consumption. A large part of the fracture, however, consists of facets of cleavage decohesion. These are facets formed by the separation of phase boundaries, but the mechanism of their failure is the cleavage, i.e., low energy. These surfaces are shown in Figure 16 and are characteristic for the cast state of the cladding without thermal treatment.

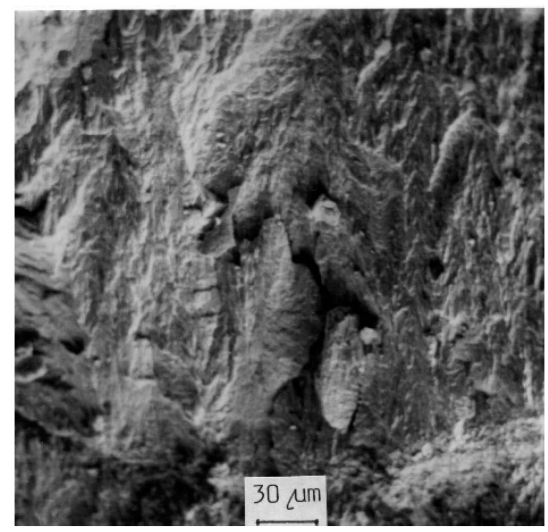

Figure 15. Fracture surface of cladding E 518 B.

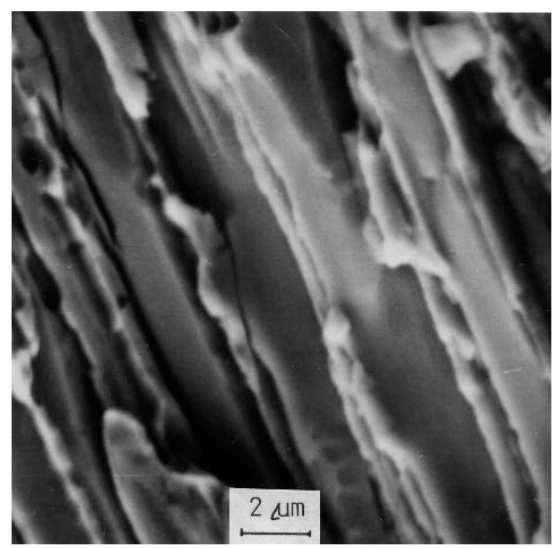

Figure 16. Detail of decohesive failure.

The stated information implies that claddings made by electrode $\mathrm{E} 508 \mathrm{~B}$ have a tough bainitic matrix dispersely reinforced by a carbidic phase, as shown in Figure 17. This symbiosis of the matrix and disperse carbidic reinforcement optimizes the abrasive wear resistance. The structure has a high density of dislocations whose movement is intensively stopped by the disperse phase, as shown in Figure 18. Plastic deformation thus requires high stress for the movement of the dislocations. It is known that the bainitic structures with the same chemical compositions optimize mechanical properties, i.e., at high levels of strength (hardness) they retain adequate ductility. 


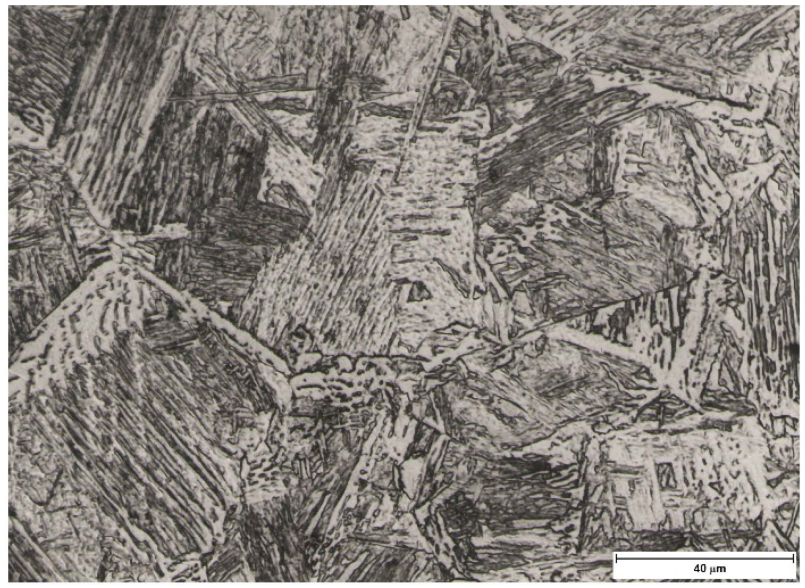

Figure 17. Bainitic matrix containing carbides.

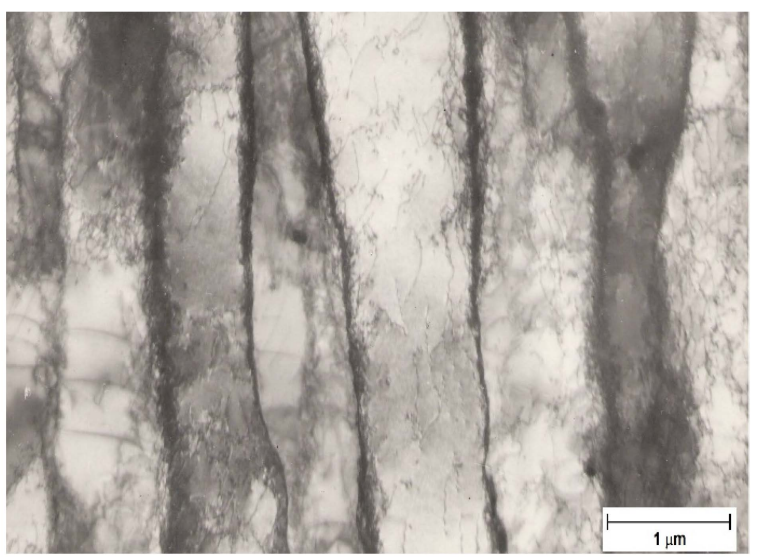

Figure 18. Dislocations in bainitic matrix.

The structure of claddings made by electrode $\mathrm{E} 518 \mathrm{~B}$ is ledeburitic due to the high content of carbon and the high content of chrome. There are primary as well as secondary carbides present in the structure, morphologically formed massively as well as dispersely, a shown in Figure 19. The dislocation state is high, represented mainly by anchored dislocations.

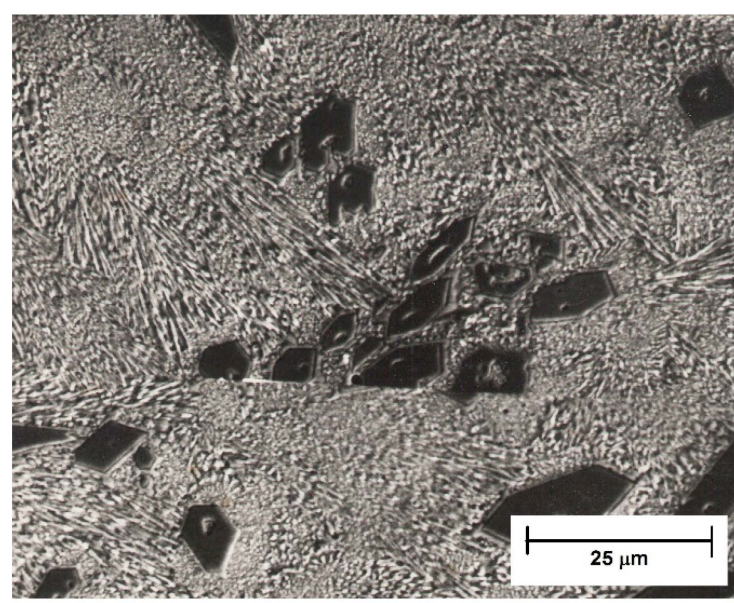

Figure 19. Carbides in ledeburitic structure. 
Although the material is high strength (hard), it has a small reserve of plastic deformation, and therefore it is brittle. The low strength of the grain boundaries is also added to these properties. It can therefore be concluded that the cohesive strength of the boundaries and subboundaries is significantly lower than the strength of the matrix. The material separation is realized by the decohesion of particles and the separation by the cleaving mechanism.

\section{Conclusions}

Based on the achieved results of the study of the structural composition of claddings, the measurements of their hardness and their abrasive wear resistance, the following can be concluded:

1. The hardness and wear values confirm the correctness of the principle that the optimal properties are not achieved by hardfaced materials until the third layer. For practical application it is necessary to execute the welding process with minimal melting of the base material. In the cladding by electrode $\mathrm{E} 518 \mathrm{~B}$, due to its chemical composition, this effect was less pronounced.

2. In set conditions of wear, the claddings made by electrode E $508 \mathrm{~B}$ seem more favorable. The tough bainitic matrix dispersely reinforced by a carbidic phase provides good resistance to abrasive wear. In terms of chemical composition and manufacturing technology, these claddings appear economical since they can be realized without a special regime of hardfacing. Cladding has excellent properties without a heat treatment.

3. Claddings made by electrode E 518 B, in terms of hardness values, appear to be of high quality. The formation of the ledeburitic structure with plenty of carbidic phase gives a high-strength though brittle cladding. Claddings therefore have little resistance to abrasive wear in combination with mild impacts.

4. Based on the obtained results, it can be concluded that in the optimized chemical composition of weld materials, it is necessary to also take the structural constitution of the cladding into consideration. Better results are obtained in two-component structural phases where the matrix has sufficient hardness with a good supply of plastic properties and the reinforcing disperse component is based on a carbidic or carbonitridic basis.

Acknowledgments: This work was supported by the Slovak Research and Development Agency under the contract No. SK-UA-2013-0013 and project VEGA No. 1/0600/13.

Author Contributions: Realization of hardfacing, three-point bending, abrasive tests-Ján Viňáš, Peter Balog. Metallography analysis, analysis of fracture, hardness testing-Janette Brezinová, Dagmar Draganovská, Anna Guzanová.

Conflicts of Interest: The authors declare no conflict of interest.

\section{References}

1. Viňáš, J.; Brezinová, J.; Guzanová, A.; Svetlík, J. Degradation of renovation layers deposited on continuous steel casting rollers by submerged arc welding. Proc. Inst. Mech. Eng. B 2013, 227, 1841-1848. [CrossRef]

2. Viňáš, J.; Brezinová, J.; Guzanová, A. Analysis of the quality renovated continuous steel casting roller. Sadhana 2013, 38, 477-490. [CrossRef]

3. Viňáš, J.; Brezinová, J.; Guzanová, A.; Balog, P. Evaluation of the quality of cladding deposited on continuous steel casting rolls. Int. J. Mater. Res. 2013, 104, 183-191. [CrossRef]

4. Correaa, E.O.; Alcântara, N.G.; Valeriano, L.C.; Barbedo, N.D.; Chaves, R.R. The effect of microstructure on abrasive wear of a Fe-Cr-C-Nb hardfacing alloy deposited by the open arc welding process. Surf. Coat. Technol. 2015, 276, 479-484. [CrossRef]

5. Jankauskas, V.; Antonov, M.; Varnauskas, V.; Skirkus, R.; Goljandin, D. Effect of WC grain size and content on low stress abrasive wear of manual arc welded hardfacings with low-carbon or stainless steel matrix. Wear 2015, 328-329, 378-390. [CrossRef]

6. Blaškovič, P.; Čomaj, M. Renovácia Naváraním a Žiarovým Striekaním; Alfa: Bratislava, Slovakia, 1991.

7. Dwivedi, D.K. Abrasive wear behavious of iron based hard serfacing alloy coatings developed by welding. Surf. Eng. 2004, 20, 87-92. [CrossRef] 
8. Senthilkumar, B.; Kannan, T. Effect of flux cored arc welding process parameters on bead geometry in super duplex stainless steel claddings. Measurement 2015, 62, 127-136. [CrossRef]

9. Czichos, M. Tribology; Elsevier: Oxford, UK; New York, NY, USA, 1978.

10. Marinescu, I.D.; Hitchiner, M.P.; Uhlmann, E.; Rowe, W.B.; Inasaki, I. Handbook of Machining with Grinding Wheels; CRC Press: New York, NY, USA, 2007; p. 593.

11. Malkin, S.; Guo, C. Grinding Technology: Theory and Applications of Machining with Abrasives; Industrial Press: New York, NY, USA, 2008; p. 372.

12. Abušinov, A. Nanostrukturní návary a žárové nástřiky. MM Průmyslové Spektrum 2011, 4, 22-24.

13. Brožek, M. Výsledky zkoušek abrazivního opotřebení vrstev. In Proceedings of the Conference Renop 92, Trnava, Slovakia, 17-19 March 1992; pp. 139-142.

14. Hawk, J.A.; Wilson, R.D. Abrasive Wear Failures; ASM Handbook; ASM International: Materials Park, $\mathrm{OH}$, USA, 2002; Volume 11, pp. 906-921.

15. Adamka, J.; Petríková, G. Vplyv štruktúry návarov na odolnost' proti abrazívnemu opotrebeniu. In Proceedings of the Conference Intertribo 93, Bratislava, Slovakia, 26-28 August 1993; pp. 70-76.

16. Jankura, D. Tribologické vlastnosti viacvrstvových tvrdonávarov. In Proceedings of the Conference Funkčné Povrchy, Trenčín, Slovakia, 14-16 June 2001; pp. 96-102.

17. Jankura, D. Hodnotenie vlastností viacvrstvových tvrdonávarov. Mechanika 1996, 47, 59-66.

(C) 2016 by the authors; licensee MDPI, Basel, Switzerland. This article is an open access article distributed under the terms and conditions of the Creative Commons by Attribution (CC-BY) license (http:/ / creativecommons.org/licenses/by/4.0/). 